\title{
REMODELING OF THE BONE TISSUE OF RATS OF DIFFERENT LINES AFTER MELATONIN EFFECT
}

\author{
Uliana Zhernoklov \\ Department of Clinical Pathophysiology \\ Bogomolets Institute of Physiology, National Academy of Sciences of Ukraine \\ 4 Bogomoltsa str., Kyiv, Ukraine, 01601 \\ zhernoklev.ulyana@gmail.com \\ Vadim Berezovskyi \\ Department of Clinical Pathophysiology \\ Bogomolets Institute of Physiology, National Academy of Sciences of Ukraine \\ 4 Bogomoltsa str., Kyiv, Ukraine, 01601 \\ vadber@biph.kiev.ua \\ Irina Litovka \\ Department of Clinical Pathophysiology \\ Bogomolets Institute of Physiology, National Academy of Sciences of Ukraine \\ 4 Bogomoltsa str., Kyiv, Ukraine, 01601 \\ E-litir@biph.kiev.ua
}

\begin{abstract}
The markers of remodeling of bone tissue (BT) were studied after the impact of pharmacologic dose of melatonin $(5 \mathrm{mg} / \mathrm{kg}$ of the animal body weight) during 28 days for 3-months rats-males of Wistar and SHR lines. The studies were carried out in autumn.

The aim of our work was to study the indices of bone tissue remodeling of rats of Wistar and SHR lines after introduction of pharmacologic dose of exogenous melatonin.

Biochemical and immune-enzyme methods of analysis were used in the study. In rats of Wistar line was revealed a reliable increase of activity of alkaline phosphatase (ALP) by 43,9\% ( $<<0,05)$, hyaluronidase activity (HA) by $15,4 \%$ and free thyroxin concentration (fT4) by $30 \%$. There was also registered the decrease of pyridinoline (PYD) concentration by $48 \%$ and glycosaminoglycan (GAG) by $46,7 \%$. In rats of SHR line under the same conditions the results essentially differed. The activity of acid phosphatase (ACP) has a tendency to increase by $11,6 \%$, and PYD concentration decreased by $25 \%$. The concentrations of free triiodothyronine (fT3) and fT4 reliably increased by $51,3 \%$ and $31,1 \%$ respectively.

In the result of research we revealed that melatonin plays the main role among several main factors of regulation of bone tissue remodeling. It has stimulating influence on bone tissue and hormones of thyroid gland.
\end{abstract}

Keywords: melatonin, bone tissue, hormones of thyroid gland.

\section{Introduction}

Melatonin plays the node role as paracrine signal molecule for local coordination of cellular functions and intercellular connections. At the same time it can acts also as typical hormone for remote cells-targets. The main effects of melatonin impact on bone tissue are: stimulation of differentiation and activation of osteoblasts, deceleration of differentiation of osteoclasts, neutralization of free radicals, created by osteoclasts, intensification of synthesis of collagen and non-collagen proteins of bone matrix [1-3]. There are also other hypotheses as to melatonin influence on these processes. The dependence between the high concentration of melatonin in blood plasma of ratsmales of Wistar line and low level of markers of bone tissue formation was shown [4]. In other study the effects of melatonin impact on osteoblasts culture at presence of osteoclasts were analyzed. The inhibition of activity of both types of cells was revealed that gave a possibility to make a conclusion about balance between them [5, 6]. The authors underline the importance of intercellular interaction between osteoblasts and osteoclasts for understanding their physiological activity as well as reaction to melatonin addition. 
The influence of exogenous melatonin on BT can be intensified at the expense of increase of thyroid gland hormones. Molecular mechanisms of this process are difficult and only partially studied. TG hormones have direct or indirect effect on BT. For example fT3 can induce differentiation and inhibit proliferation of osteoblasts. It was shown, that fT3 increases expression of several gens-regulators of bone metabolism, including activity of osteocalcin and synthesis of collagen type I. Free triiodothyronine (fT3) takes part in formation and mineralization of bone matrix [7].

The functional connection between melatonin and thyroid hormones can be realized by different mechanisms. From the one hand, fT3 stimulates osteogenesis by direct influence on osteoblasts and chondrocytes. From the other one, fT3 initiates BT resorption through mediate mechanisms of influence on osteoblasts. It is known that BT metabolism directly depends on TG hormone - thyroxin [8, 9]. Thyroid hormones stimulate activity of both osteoblasts and osteoclasts in trabecular and cortical BT. At the same time they take part in regulation of intrastitial and enchondral ossification [10].

The studies, devoted to the influence of pharmacological zone of melatonin on BT and TG status, were carried out on the rats of Wistar line. We did not reveal works that study melatonin influence on these tissues in animals or people with arterial hypertension. On the average arterial pressure in the rats of Wistar line under normal conditions is $120-130 \mathrm{~mm}$ of mercury column. In the rats of SHR line this parameter is $180-200 \mathrm{~mm}$ of mercury column. It cannot be excluded, that melatonin influence on rats with raised arterial pressure can lead to other changes of BT functional status comparing with normotensive rats. So, the expedience of such researches on rats with different level of arterial pressure appears.

\section{Aim}

To study the indices of remodeling of bone tissue of Wistar and SHR rats after administration of pharmacological dose of exogenous melatonin.

\section{Materials and methods}

The study was carried out on the young 3 month old rats of Wistar and SHR lines in autumn (October-November). 48 animals were used in experiment: 24 rats of Wistar line and $24-$ SHR. The rats of both lines were divided in groups, 12 animals in each one: I - control group, II - group of animals that melatonin was administered in. The animals were received from nursery of vivarium of Institute of physiology named after O. O. Bogomolets, NAS of Ukraine. They were kept in standard conditions of vivarium at natural cycle light/darkness and received the ordinary food allowance.

The animals underwent the peroral administration of $1 \mathrm{ml}$ of melatonin water suspension (Unipharm Inc., USA) at 10.00 a.m. during 28 days in pharmacological dose $5 \mathrm{mg} / \mathrm{kg}$. The control rats received at the same time equivalent quantity of physiological solution.

Using the standard sets of reagents in the blood serum of rats (blood sampling was carried out at 28 day of experiment at once after decapitation of animal) were determined: the alkaline phosphatase (ALP, "Lachema", Czechia) - index of bone tissue formation and also acid phosphatase (ACP, "BioSystems", Spain, tartrate resistant acid phosphatase (TRACP, "BioSystems", Spain), glycosaminglycans by orcine method by Klyatskin (GAG) [11], pyrindonoline (PYD) ("Quidel Corporation", USA) - as resorption parameters. In BT extract hyaluronidase activity was measured by P. N. Sharaev method (HA) [12]. In the blood serum fT3 and fT4 concentrations were determined by hard-phase concurrent enzyme-linked immune-sorbent assay (ELISA) using monoclonal antibodies ("Diagnostic systems", Russia). The measuring was carried out on immune-enzyme analyzer of Stat Fax 2100 (country-producer USA).

Statistical analysis of the received results was carried out on personal computer using the program ANOVA. The arithmetical mean (M) and standard mistake (m) were determined. The reliability of difference between control and experimental samples was assessed by Student t-criterion (Table 1).

\section{Results of research}

We give the fact data of bone tissue remodeling indices after administration of pharmacological dose of melatonin (Table 1). 
Table 1

Fact data, used for statistical analysis $(\mathrm{M} \pm \mathrm{m}, \mathrm{n}=12)$

\begin{tabular}{|c|c|c|c|c|c|c|c|}
\hline & & & Wistar & & & SHR & \\
\hline Index & $\begin{array}{c}\text { Unit of } \\
\text { measurement }\end{array}$ & $\begin{array}{l}\text { Group I } \\
\text { (control) }\end{array}$ & $\begin{array}{c}\text { Group II } \\
\text { (melatonin5 } \mathrm{mg} / \mathrm{kg} \\
\text { of body mass) }\end{array}$ & $\Delta, \%$ & $\begin{array}{l}\text { Group I } \\
\text { (control) }\end{array}$ & $\begin{array}{l}5 \mathrm{mg} / \mathrm{kg} \text { of } \\
\text { body mass) }\end{array}$ & $\Delta, \%$ \\
\hline ALP & $\mathrm{MU} / 1$ & $30,36 \pm 1,891$ & $43,68 \pm 3,41^{*}$ & $+43,9$ & $25,87 \pm 1,305$ & $11,86 \pm 2,949 * * *$ & $-54,14$ \\
\hline $\mathrm{ACP}$ & MU/1 & $44,10 \pm 7,186$ & $36,96 \pm 5,77$ & $-16,2$ & $25,31 \pm 3,194$ & $28,25 \pm 6,110$ & $+11,6$ \\
\hline TRACP & $\mathrm{MU} / 1$ & $26,1 \pm 1,2$ & $22,9 \pm 2,0$ & $-12,1$ & $15,2 \pm 1,3$ & $16,63 \pm 1,9$ & $+9,4$ \\
\hline GAG & $\mathrm{g} / 1$ & $0,30 \pm 0,01$ & $0,16 \pm 0,015^{*}$ & $-46,7$ & $0,17 \pm 0,03$ & $0,14 \pm 0,014$ & $-17,6$ \\
\hline HA & Mcm/hour & $673,0 \pm 33,407$ & $776,87 \pm 28,504 *$ & $+15,4$ & $700,66 \pm 39,11$ & $728,28 \pm 37,288$ & $+3,9$ \\
\hline PYD & $\mathrm{nM} / 1$ & $2,51 \pm 0,4$ & $1,3 \pm 0,2 * *$ & -48 & $2,4 \pm 0,4$ & $1,8 \pm 0,08$ & -25 \\
\hline $\mathrm{fT} 3$ & $\mathrm{Pg} / \mathrm{ml}$ & $4,3 \pm 0,2$ & $4,9 \pm 0,6$ & +14 & $3,9 \pm 0,3$ & $5,9 \pm 0,4 * * *$ & $+51,3$ \\
\hline fT4 & $\mathrm{Pmol} / 1$ & $17,1 \pm 1$ & $22,3 \pm 2,1^{*}$ & +30 & $19,6 \pm 1,1$ & $25,7 \pm 1,7 * *$ & $+31,1$ \\
\hline
\end{tabular}

Note: $*-P<0,05, * *-P<0,01, * * *-P<0,001$ - comparing with control group of animals

According to the received data, in the rats of Wistar line after peroral administration of melatonin ALP activity in blood serum grew by $43,9 \%(\mathrm{P}<0,05)$, and in SHR, on the contrary, decreased by $54,14 \%$ (*** $\mathrm{P}<0,001)$ comparing with control values (Fig. 1).

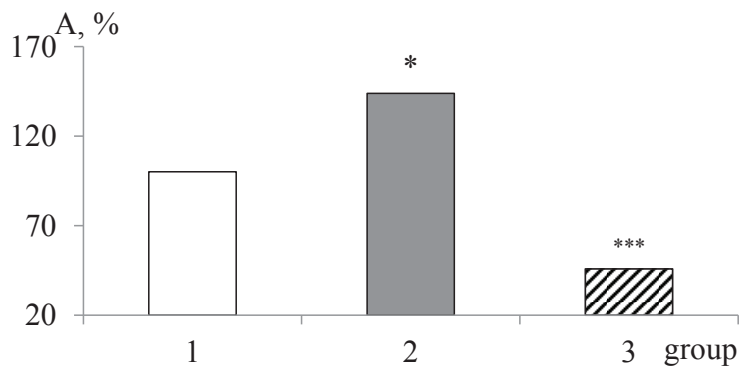

Fig. 1. Activity of alkaline phosphatase in the blood serum of young rats of the control group (1) and after melatonin administration in animals of Wistar (2) and SHR (3) lines: * $-\mathrm{P}<0,05$, *** $-\mathrm{P}<0,001$ - comparing with control group - the fact data of control groups Wistar and SHR were considered as $100 \%$ (Table 1)

In the rats of Wistar line ACP and TRACP activity in the blood serum expressed a tendency to decrease by $16,2 \%$ and $12,1 \%$ respectively. In animals of SHR these indices under the same conditions had tendency to increase by $11,6 \%$ - ACP, and 9,4 \% - TRACP.

Determining GAG, PYD and HA concentrations, we studied the main biochemical mechanism of collagen and proteoglycans metabolism in BT. GAG - are the acid polysaccharides that are contained in proteoglycans. They support the integrity of organic and non-organic component of extracellular matrix of tissue and take part in fibril collagen creation. Hyaluronidase activity (HA) - is combined action of two lysosomal enzymes of hyaluronoglucosoaminidase and hyaluronoglucorodinase that decompose GAG in BT. Pyridinoline (PYD) acts as pyridine seams of mature collagen molecules. It plays an important role in its stabilization and provides specific biological properties for creation of collagen and elastin structures. Under conditions of BT resorption, realized by osteoplasts, and collagen destruction, PYD "comes out" in vessel channel. The aforesaid indices reflect the active processes of BT remodeling under normal conditions [13].

GAG concentration in the blood serum of Wistar rats reliably decreased by $46,7 \%(\mathrm{P}<0,05)$ comparing with control. In SHR animals this index did not change (Fig. 2). 


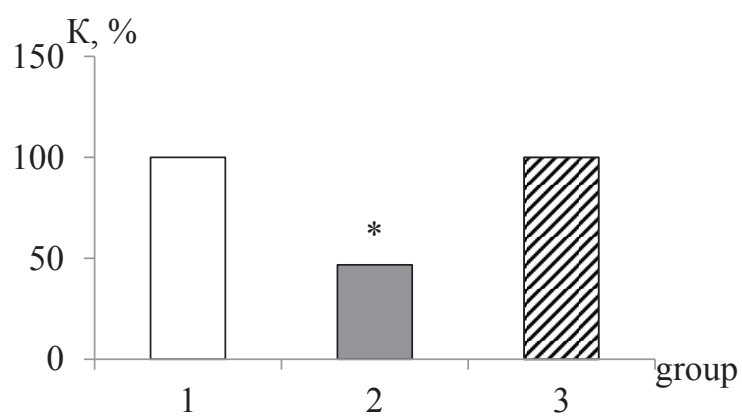

Fig. 2. Glycosaminoglycans concentration in the blood serum of young rats from the control group (1) and after melatonin administration to Wistar (2) and SHR (3) animals:

* $-\mathrm{P}<0,05$ - comparing with control group of animals

In Wistar rats hyalurodinase activity reliably grew by $15,4 \%$. In group of SHR animals this index did not change (Fig. 3).

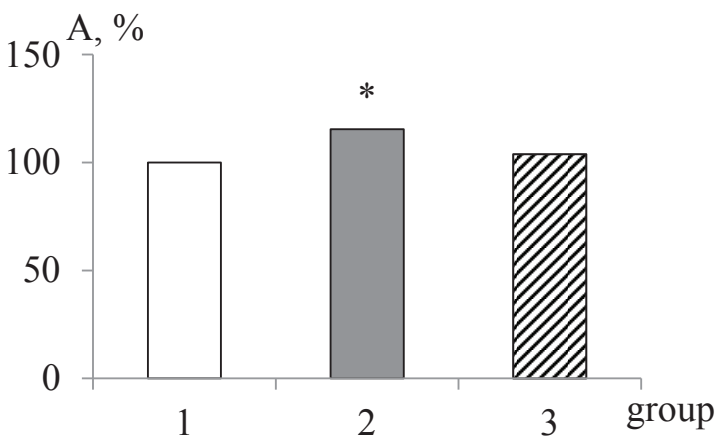

Fig. 3. Hyaluronidase activity in the blood serum of young rats from the control group (1) and after melatonin administration to Wistar (2) and SHR (3) animals: * $-\mathrm{P}<0,05$ - comparing with control group of animals - the fact data of control groups Wistar and SHR were considered as $100 \%$ (Table 1)

PYD concentration reliably decreased by $48 \%$ in Wistar animals and had tendency to decrease by $25 \%$ in SHR comparing with control (Fig. 4).

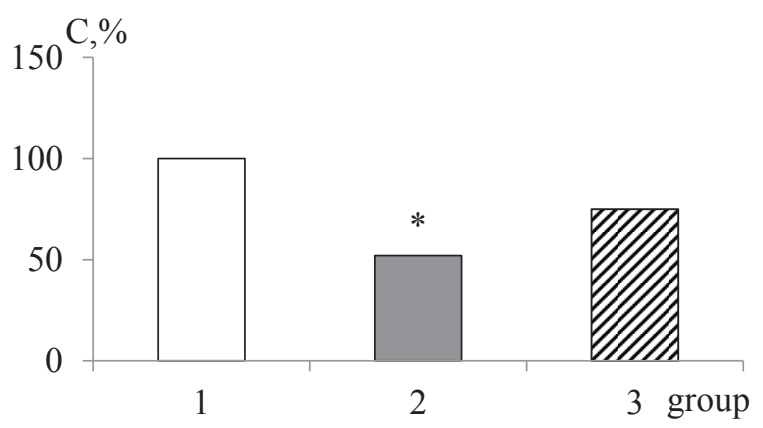

Fig. 4. Pyridinolin concentration in the blood serum of young rats from the control group (1) and after melatonin administration to Wistar (2) and SHR (3) animals: ** $-\mathrm{P}<0,01$ - comparing with control group of animals - the fact data of control groups Wistar and SHR were considered as $100 \%$ (Table 1)

At determination of concentration of thyroid hormones fT3 and fT4 that also react to melatonin impact it was demonstrated, that Wistar animals have only tendency to increase of fT3 concentration by $14 \%$ comparing with control. In SHR line this parameter reliably increased by $51,3 \%$ comparing with control $(\mathrm{P}<0,001)$ (Fig. 5). 
fT4 concentration after melatonin administration was reliably higher by $30 \%$ in Wistar animals and by $31,1 \%$ in SHR ones comparing with control - the fact data of Wistar ans SHR control groups were considered as $100 \%$ (Table 1).

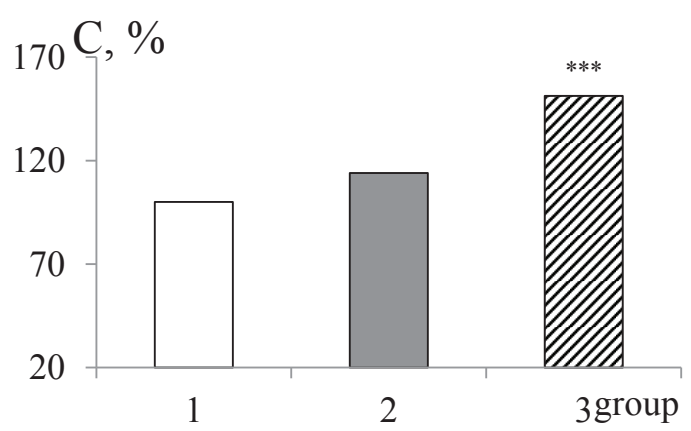

Fig. 5. Free triiodine concentration in the blood serum of young rats from the control group (1) and after melatonin administration to Wistar (2) and SHR (3) animals: *** $-\mathrm{P}<0,01$ - comparing with control group of animals

\section{Discussion of the results}

Osteoblasts and osteoclasts take part in physiological remodeling of BT. Their activity is determined by measuring of specific enzymes. For osteoblasts - it is alkali phosphatase (ALP), for osteoclasts - acid phosphatase (ACP) and tartrate resistant acid phosphotase (TRACP). At the study of these indices our hypothesis about possible difference in reactions of normotensive and hypertensive rats to the influence of exogenous melatonin in pharmacological dose was proved.

The received results testify to the fact that melatonin has different effect on these processes in Wistar and SHR rats. In Wistar rats such changes can be considered as a result of increase of number and functional activity of osteoclasts that is domination of osteoclastic type of BT resorption that is testified in literature [14]. The changes of different indices of BT metabolism, revealed in SHR rats, reflect the destruction of balance between processes of its renewal and destruction. Especially it is the decrease of osteoblasts activity without essential increase of osteoclasts activity.

At analysis of the results of our studies, reliable changes after influence of exogenous melatonin on fT3 and fT4 indices of animals of both lines, it can be noted, that in SHR it had expressively more amplitude. But in both lines the growth had one direction. The received results are agreed with literary data as to the influence of melatonin on BT formation of young animals $[6,15]$.

At the same time having analyzed information of the literature, we revealed that exogenous melatonin in pharmacological dose inhibited fT4 level in group of 2 and 4-month male mice. In 8-month male mice melatonin, according to literary data, increased fT4 level [16]. The studies, carried out on mutant mice demonstrated that fT3 takes part in anabolic and catabolic processes of BT growth [17]. BT is extremely sensitive tissue-target for fT3. It testifies to the important role of thyroid hormones in process of BT growth, development and metabolism [18-21].

Pharmacological doses of melatonin in autumn period intensify thyroid activity, and increase of TG function essentially influences the structural-metabolic indices of BT state.

The differences between the received data of activity of biochemical parameters of BT remodeling and TG hormones concentration in animals of Wistar and SHR lines testify to the fact that melatonin in pharmacological dose has different influence on animals with different level of arterial pressure (Fig. 6). 

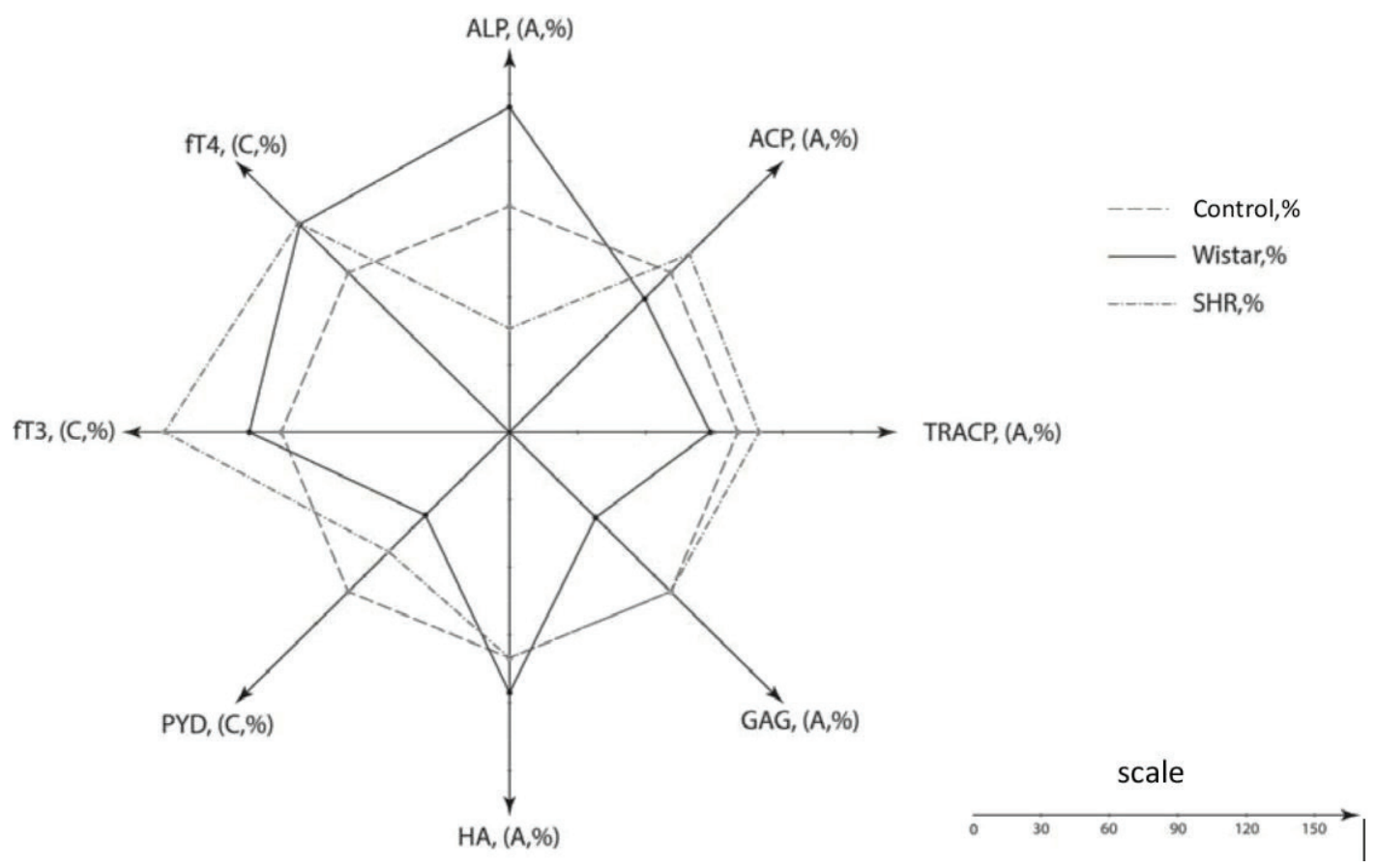

Fig. 6. Reaction of biochemical and hormone markers of bone tissue remodeling before and after administration of melatonin on young rats of Wistar and SHR lines in autumn

\section{Conclusions}

1. In young rats of Wistar line the administration of exogenous melatonin in pharmacological dose ( $5 \mathrm{mg} / \mathrm{kg}$ of body mass) essentially influences the markers of bone tissue physiological remodeling: activity of alkaline phosphatase reliably increased by $43,9 \%$, hyalurodinase activity by $15,4 \%$ free thyroxin concentration - by $30 \%$. Glycosaminoglycans and pyridinolin decreased almost by $50 \%$.

2. In the rats of SHR line administration of exogenous melatonin ( $5 \mathrm{mg} / \mathrm{kg}$ of body mass) leads to the reliable decrease of alkaline phosphadase activity by $54,15 \%$, increase of free triiodothyronine concentration $51,3 \%$ and by $31,1 \%$ - free thyroxin concentration that can testify to the disturbance of balance between the processes of renewal and destruction of bone tissue. And especially it is decrease of osteoblasts activity without essential increase of osteoclasts one.

3. Melatonin plays the important role in bone tissue remodeling by the influence on endogenous endocrine factors.

\section{References}

[1] Liu, J., Huang, F., He, H.-W. (2013). Melatonin Effects on Hard Tissues: Bone and Tooth. International Journal of Molecular Sciences, 14 (5), 10063-10074. doi: 10.3390/ijms140510063

[2] Anisimov, V. N., Vinogradova, I. A., Bukalov, A. V. (2013). Light desynhronisation risk of malignancies in humans: the state of the problem. Problems of oncology, 59 (3), 302-313.

[3] Ostrowska, Z., Wolkowska-Pokrywa, K., Kos-Kudla, B., Swietochowska, E., Marek, B., Kajdaniuk, D. (2006). Melatonin and bone status. Pol Merkur Lekarski, 21 (124), 389-393.

[4] Satomura, K., Tobiume, S., Tokuyama, R., Yamasaki, Y., Kudoh, K., Maeda, E., Nagayama, M. (2007). Melatonin at pharmacological doses enhances human osteoblastic differentiation in vitro and promotes mouse cortical bone formation in vivo. Journal of Pineal Research, 42 (3), 231-239. doi: 10.1111/j.1600079x.2006.00410.x

[5] Sethi, S., Radio, N. M., Kotlarczyk, M. P., Chen, C.-T., Wei, Y.-H., Jockers, R., Witt-Enderby, P. A. (2010). Determination of the minimal melatonin exposure required to induce osteoblast differentiation from human mesenchymal stem cells and these effects on downstream signaling pathways. Journal of Pineal Research, 49 (3), 222-238. doi: 10.1111/j.1600-079x.2010.00784.x 
[6] Cardoso, L. F., Maciel, L. M. Z., de Paula, F. J. A. (2014). The multiple effects of thyroid disorders on bone and mineral metabolism. Arquivos Brasileiros de Endocrinologia \& Metabologia, 58 (5), 452-463. doi: 10.1590/0004-2730000003311

[7] Waung, J. A., Bassett, J. H. D., Williams, G. R. (2012). Thyroid hormone metabolism in skeletal development and adult bone maintenance. Trends in Endocrinology \& Metabolism, 23 (4), 155-162. doi: 10.1016/j.tem.2011.11.002

[8] Bassett, J. H. D., Williams, A. J., Murphy, E., Boyde, A., Howell, P. G. T., Swinhoe, R. et. al. (2008). A Lack of Thyroid Hormones Rather than Excess Thyrotropin Causes Abnormal Skeletal Development in Hypothyroidism. Molecular Endocrinology, 22 (2), 501-512. doi: 10.1210/me.2007-0221

[9] Bassett, J. H. D., Williams, G. R. (2016). Role of Thyroid Hormones in Skeletal Development and Bone Maintenance. Endocrine Reviews, 37 (2), 135-187. doi: 10.1210/er.2015-1106

[10] Bassett, J. H. D., Nordström, K., Boyde, A., Howell, P. G. T., Kelly, S., Vennström, B., Williams, G. R. (2007). Thyroid Status during Skeletal Development Determines Adult Bone Structure and Mineralization. Molecular Endocrinology, 21 (8), 1893-1904. doi: 10.1210/me.2007-0157

[11] Klyatskin, S. A., Lifshitz, R. I. (1989). Determination of glycosaminoglycans by ortsin method in patients' blood. Laboratory work, 10, 51-53.

[12] Sharaev, P. N., Strelkov, N. S., Guncha, V. V., Sosulina, L. L. (1996). Determination of hyaluronidase activity in biological fluids. Clinical laboratory diagnostics, 3, 21-22.

[13] Litovka, I. G., Berezovsky, V. A. (2014). The organic matrix in the adaptation and remodeling of bone. Donetsk, 255.

[14] Zou, W., Kitaura, H., Reeve, J., Long, F., Tybulewicz, V. L. J., Shattil, S. J. et. al. (2007). Syk, $\mathrm{c}-\mathrm{Src}$, the $\alpha \mathrm{v} \beta 3$ integrin, and ITAM immunoreceptors, in concert, regulate osteoclastic bone resorption. The Journal of Cell Biology, 176 (6), 877-888. doi: 10.1083/jcb.200611083

[15] Satomura, K., Tobiume, S., Tokuyama, R., Yamasaki, Y., Kudoh, K., Maeda, E., Nagayama, M. (2007). Melatonin at pharmacological doses enhances human osteoblastic differentiation in vitro and promotes mouse cortical bone formation in vivo. Journal of Pineal Research, 42 (3), 231-239. doi: 10.1111/j.1600079x.2006.00410.x

[16] Prashanjit, L., Samik, A., Singh, S. S. (2015). Effect of Exogenous Melatonin on Thyroxine (T4), Thyrotropin (TSH) Hormone Levels and Expression patterns of Melatonin Receptor (MT1 and MT2) Proteins on Thyroid gland during Different age groups of Male and Female Swiss albino Mice. Advances in Bioresearch, 6 (1), 7-14.

[17] Belviranli, M., Baltaci, A. K. (2007). The relation between reduced serum melatonin levels and zinc in rats with induced hypothyroidism. Cell Biochemistry and Function, 26 (1), 19-23. doi: 10.1002/ cbf. 1384

[18] Bassett, J. H. D., Williams, G. R. (2016). Role of Thyroid Hormones in Skeletal Development and Bone Maintenance. Endocrine Reviews, 37 (2), 135-187. doi: 10.1210/er.2015-1106

[19] Quignodon, L., Vincent, S., Winter, H., Samarut, J., Flamant, F. (2007). A Point Mutation in the Activation Function 2 Domain of Thyroid Hormone Receptor $\alpha 1$ Expressed after CRE-Mediated Recombination Partially Recapitulates Hypothyroidism. Molecular Endocrinology, 21 (10), 2350-2360. doi: 10.1210/ me.2007-0176

[20] Desjardin, C., Charles, C., Benoist-Lasselin, C., Riviere, J., Gilles, M., Chassande, O. et. al. (2014). Chondrocytes Play a Major Role in the Stimulation of Bone Growth by Thyroid Hormone. Endocrinology, 155 (8), 3123-3135. doi: 10.1210/en.2014-1109

[21] Bassett, J. H. D., Boyde, A., Zikmund, T., Evans, H., Croucher, P. I., Zhu, X. et. al. (2014). Thyroid Hormone Receptor $\alpha$ Mutation Causes a Severe and Thyroxine-Resistant Skeletal Dysplasia in Female Mice. Endocrinology, 155 (9), 3699-3712. doi: 10.1210/en.2013-2156 